\title{
Editorial for EAIT 2016, Issue 3
}

\author{
Arthur Tatnall ${ }^{1}$
}

Published online: 29 March 2016

(C) Springer Science+Business Media New York 2016

Some of you will have read the 2015 OECD report: "Students, Computers and Learning: Making the Connection" which indicates that, based on an analysis of PISA data, where ICT is used in the classroom its impact on student performance is mixed, with no appreciable improvements in student achievement in reading, mathematics or science. Is the OECD right in their assessment? Are we wasting our time with using ICT in education? How do others see this? It would be good to have some articles on this important topic in future issues of EAIT.

Beginning this issue is an article from Martin Tallvid (University of Gothenburg, Sweden), titled: "Understanding teachers' reluctance to the pedagogical use of ICT in the 1:1 classroom". The article begins by noting the emergence of one laptop per student-initiatives $(1: 1)$ as a solution to disappointment with the pace of transformation of teaching methods in schools. Many research studies, however, have indicated that despite major expenditure, increased access and improved technical equipment, few teachers have integrated ICT in the curriculum in a way that leads to significant changes in classroom practice. The article explores teachers' reluctance towards the pedagogical use of personal laptops in secondary schools and identifies five different, but overlapping, patterns in the explanations for their reluctance: lack of technical competence, not worth the effort, insufficient material, diminishing control and lack of time.

"Politic of security, privacy and transparency in human learning systems" is an article by Adil Jeghal, Lahcen Oughdir and Hamid Tairi (University of Sidi Mohamed Ben Abdellah, Taza, Morocco). This article looks at the important role of Information Security, especially in newer education environments such as e-learning environments. The authors point out that the preservation of confidentiality has become a major issue for the majority of applications that process personal information and that the sensitivity of this information requires creators to set rules for the sharing and use of access control policies.

Arthur Tatnall

Arthur.Tatnall@vu.edu.au

1 Victoria University, PO Box 14428, Melbourne 8001, Australia 
David Passig and Jenny Maidel-Kravetsky (Bar-Ilan University, Israel) next present: "The impact of collaborative online reading on summarising skills". The aim of their study was to determine whether, as a result of collaborative online reading of a chapter from an academic book, the quality of the collaborative summary that the readers would write would be higher than that written by readers who would both read the same chapter and write a summary in a face-to-face setting. The participants of the experimental group read the chapter as it appeared in a website for collaborative reading built especially for this study and the participants were asked to summarise the chapter on a shared online digital document. The participants of the control group were asked to read the chapter face-to-face and to collaboratively summarise it in hand writing. The findings indicated that there were significant differences in the majority of the writing indicators and that collaborative-online reading and writing produce a summary of a higher quality than one read and hand written collaboratively face-to-face.

"Everyday personal laptop usage in secondary schools in Trinidad and Tobago" by Georgette Briggs and Erik Blair (University of the West Indies, St Augustine, Trinidad and Tobago) follows. Their article provides a snapshot of how students are using the Trinidad and Tobago government 'e-Connect And Learn (eCAL)' programme that grants personal laptop computers to students entering secondary school. Their study showed that students are falling short of the expectations for in-class laptop usage. In schools where usage is less often but on a regular basis, laptops are mainly used for technology-related subjects. Their findings not only suggest that students' everyday personal laptop usage in the classroom is not in alignment with the eCAL programme goals, but also highlight some of the issues to be considered by other countries when implementing large-scale laptop programmes.

In "Designing and deploying programming courses: Strategies, tools, difficulties and pedagogy" Stelios Xinogalos (University of Macedonia, Egnatia) points out that this design and deployment is undoubtedly a challenging task. The article analyses important aspects of a sequence of two courses on imperative-procedural and object-oriented programming in a non-CS majors Department. Issues investigated refer to: the strategy selected for the introduction to programming, the sequence of the programming techniques and languages taught and the transition from the one to the other, students' difficulties with programming in general and with imperative-procedural and objectoriented programming specifically, the teaching and learning design of both courses, and the material that students rely on for learning programming. The research's main results refer to the usage of a pseudo-language for an introduction to programming, the transition from procedural to object-oriented programming, the intrinsic difficulties of learning programming, and practices for a more successful teaching and learning design of programming courses.

Nicholas Zaranis (University of Crete) next contributes an article outlining a study to investigate if information and communications technology helps improve kindergarten students' basic mathematical achievement in addition. The article is titled: "The use of ICT in kindergarten for teaching addition based on realistic mathematics education". The research compares the level of mathematical competence of the students taught using an ICT oriented learning method which specifically takes advantage of 'Realistic Mathematics Education' for the concept of addition, as opposed to traditional teaching methodology. The designed software consisted of a story and several activities with and without the use of computers for addition. The results of the study indicated that 
teaching and learning through ICT at the kindergarten level has a positive effect for the learning of addition using the background of 'Realistic Mathematics Education' theory.

"School websites as a novel internationalisation assessment tool" by Miri Yemini and Anat Cohen (Tel Aviv University, Israel) presents a case study on internationalisation assessment. The international, intercultural and global dimensions at the school level are examined, focusing on the case of one particular secondary school in Israel. A novel, practical assessment tool is presented for the measurement of internationalisation intensity and scope at the school level, based on systematic analysis of school websites and adapted from existing assessment tools for higher education institutions. It was found that internationalisation processes take place in each of the tested domains, although a large variation was found in intensity and appearance.

"ICT in Portuguese reference schools for the education of blind and partially sighted students" is an article by Sara Isabel Moça Ramos and António Manuel Valente de Andrade (Catholic University of Portugal). The authors note that technology has become an essential component in our society and when considering its impact in the educational system, ICT cannot be dissociated from the educational process and, in particular, from pedagogical practices adopted for students who are blind or partially sighted. The study analysed the perceptions of teachers who teach visually impaired students in middle and secondary school education, of their knowledge, teaching and training in the area of ICT, as well as of the real ICT integration in the teaching and learning of these students. The implementation of ICT with students who have visual disabilities is lower compared with sighted students. The lack of specific training is considered to be the main obstacle for teachers, with regard to the real integration of ICT in the teaching and learning of these students.

The next article: "A framework for mobile apps in colleges and universities: Data mining perspective" is by Archana Singh and Jayanthi Ranjan (Amity University Uttar Pradesh, Ghaziabad, India). The authors note that enterprise mobility communication technology provides quick and easy access to data and information integrated into one single touch point device, and that the readiness and availability of data can reduce turnaround response time. The application of mobile technology has gained worldwide acceptance, but in the Indian education sector this technology is yet to be widely adopted. This paper shows how enterprise mobility can facilitate a University, and how data mining techniques can be applied to various processes. The authors propose a new model using data mining techniques.

Liisa Ilomäki, Sami Paavola, Minna Lakkala and Anna Kantosalo (University of Helsinki, Finland) write on: "Digital competence - an emergent boundary concept for policy and educational research". In the article they write that digital competence is an evolving concept related to the development of digital technology and the political aims and expectations of citizenship in a knowledge society. It is regarded as a core competence in policy papers, but that in educational research it is not yet a standardised concept. The article shows that digital competence consists of a variety of skills and competences and its scope is wide, as is its background from media studies and computer science to library and literacy studies. The authors suggest that digital competence is defined as consisting of: technical competence, the ability to use digital technologies in a meaningful way for working and studying in everyday life, the ability to evaluate digital technologies critically, and motivation to participate and commit in the digital culture. 
"Performance assessment in serious games: Compensating for the effects of randomness" by Wim Westera (Open University of the Netherlands) deals with performance assessment in serious games: those that involve a process of player-lead decision taking. Starting from combinatorics and item-response theory the article provides an analytical model that makes explicit to what extent observed player performances (decisions) are blurred by chance processes (guessing behaviours). The research found that for valid performance assessments, be it in-game or post-game, the effects of randomness should be included to produce re-calibrated scores that can reasonably be interpreted as the players' achievements.

The final article in this issue: "Bully versus victim on the internet: The correlation with emotional-social characteristics" is by Sigal Eden (Bar Ilan University) and Tali Heiman and Dorit Olenik-Shemesh (Open University, Israel). The article deals with cyberbullying which is regarded as 'a repeated violent behaviour aimed at hurting another person directed by an individual or a group towards the victim using technological means such as a computer or a mobile phone'. The reported study examined the phenomenon of cyberbullying among children and youth in Israel with the purpose of determining the correlation between bully and victim, and emotional-social aspects, social support, sense of loneliness and sense of self-efficacy that constitute risk factors and protective factors. The research found that the less social support the students have the lower their sense of self-efficacy. The lonelier they feel and the more they experience a lower sense of well-being, the greater the likelihood that they will participate in cyberbullying, mainly by sending offensive pictures or videos.

\section{Arthur Tatnall}

Editor-in-Chief 